\title{
A Educação em Saúde na área da Parasitologia: a experiência dos projetos de extensão LiPar e Educac na "Semana de meninas e mulheres na Ciência" ocorrida na Universidade do Estado do Rio de Janeiro
}

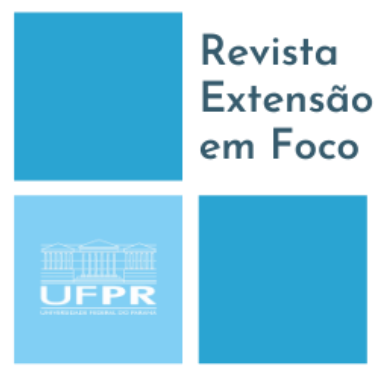

ISSN $2358-7180$

\section{Health education in parasitology: the experience of the LiPar and Educac extension projects on the Week of Girls and Women in Science at the State University of Rio de Janeiro}

\begin{abstract}
Shayane Martins Rodrigues Gomes ${ }^{1}$, Carlos Eduardo da Silva Filomeno ${ }^{2}$, Luciana Brandão Bezerra ${ }^{3}$, Cláudia Moraes Clemente Leal ${ }^{4}$, Ingrid Mendes Paschoal ${ }^{5}$, Bruno Moraes da Silva ${ }^{6}$, Beatriz Albuquerque Machado ${ }^{7}$, Julia Leonidia de Oliveira Silva, Taynara Vieira Teixeira ${ }^{9}$, Paula Ingridy Gomes Neves ${ }^{10}$, Regina Bontorim Gomes ${ }^{11}$, Karine Gomes Leite ${ }^{12}$, Jéssica Silva de Figuêredo ${ }^{13}$, Adriana Raineri Radighieri ${ }^{14}$, Tayná
\end{abstract}

\footnotetext{
${ }^{1}$ Bacharel em Ciências Biológicas. UERJ, Rio de Janeiro, RJ, Brasil. E-mail: shay.sj@gmail.com. Orcid: https://orcid.org/0000-0003-4644-1760

${ }^{2}$ Doutorando em Microbiologia Médica Humana. UERJ, Rio de Janeiro, RJ, Brasil. E-mail: carloseduardofilomeno@gmail.com. Orcid: https://orcid.org/0000-0002-4362-9066

${ }^{3}$ Doutora em Microbiologia Médica Humana. UERJ, Rio de Janeiro, RJ, Brasil. E-mail: lulithomas@gmail.com. Orcid: https://orcid.org/0000-0001-6729-8487

${ }^{4}$ Graduanda em Enfermagem. UERJ, Rio de Janeiro, RJ, Brasil. E-mail: claudiamoraes.cl@gmail.com. Orcid: https://orcid.org/0000-0002-7818-4802

${ }^{5}$ Mestranda em Microbiologia Médica Humana. UERJ, Rio de Janeiro, RJ, Brasil. E-mail: ingridmendesp@hotmail.com. Orcid: https://orcid.org/0000-0002-3197-4727

${ }^{6}$ Mestrando em Microbiologia Médica Humana. UERJ, Rio de Janeiro, RJ, Brasil. E-mail: itsbrunomoraes@gmail.com. Orcid: https://orcid.org/0000-0003-0892-792X

${ }^{7}$ Graduanda em Enfermagem. UERJ, Rio de Janeiro, RJ, Brasil. E-mail: beatriza_machado@ @otmail.com. Orcid: https://orcid.org/0000-0003-0009-146X

${ }^{8}$ Graduanda em Enfermagem. UERJ, Rio de Janeiro, RJ, Brasil. E-mail: julia.fenfuerj182@ hotmail.com. Orcid: https://orcid.org/0000-0002-0163-107X

${ }^{9}$ Bacharel e Licenciatura em Ciências Biológicas. Universidade Veiga de Almeida, Rio de Janeiro, RJ, Brasil. E-mail: taynara.vieira17@hotmail.com .Orcid: https://orcid.org/0000-0002-7984-1237

${ }^{10}$ Graduanda em Enfermagem. UERJ, Rio de Janeiro, RJ, Brasil. E-mail: ingridyneves04@gmail.com. Orcid: https://orcid.org/0000-0001-8901-5150

${ }^{11}$ Graduanda em Enfermagem. UERJ, Rio de Janeiro, RJ, Brasil. E-mail: regina.bontorim@ hotmail.com. Orcid: https://orcid.org/0000-0002-5260-4493

${ }^{12}$ Doutoranda em Microbiologia Médica Humana. UERJ, Rio de Janeiro, RJ, Brasil. E-mail: karine.leite88@gmail.com. Orcid: https://orcid.org/0000-0001-9560-6002

${ }^{13}$ Graduanda em Enfermagem. UERJ, Nova Iguaçu, RJ, Brasil. E-mail: jessy.angeel@gmail.com. Orcid: https://orcid.org/0000-0003-0077-3524

${ }^{14}$ Bacharel em Biomédica e Graduanda em Enfermagem. UERJ, Marília, SP, Brasil. E-mail: adriana.raineri@gmail.com. Orcid: https://orcid.org/0000-0002-3180-1615
} 


\title{
de Melo Ubirajara ${ }^{15}$, Isadora do Monte Silveira Bruno ${ }^{16}$, Aline Aparecida da Rosa ${ }^{17}$, Daniel Barbosa Guimarães ${ }^{18}$, Joana Bernardo Manoel Maria ${ }^{19}$, Renata Heisler Neves ${ }^{20}$
}

\begin{abstract}
RESUMO
As atividades de extensão universitária têm ganhado cada vez mais espaço, por mostrarem-se importantes instrumentos de construção do pensamento científico, colaborando para a incorporação de novos saberes e práticas para a sociedade e para os extensionistas. Os espaços não formais de ensino, por sua vez, revelamse ótimos meios para tornar a construção desses saberes possível. Logo, através da associação das atividades de extensão em espaços não formais de ensino, é possível promover as temáticas de educação em saúde em parasitologia, buscando conscientizar e prevenir, de modo criativo e ativo, as parasitoses que ainda são um grande problema de saúde pública. Desta forma, esse trabalho se propôs relatar a experiência dos projetos de extensão da Universidade do Estado do Rio de Janeiro, LiPar (Liga de Parasitologia) e Educac, no evento "Semana de Meninas e Mulheres na Ciência", organizado por mulheres de diferentes áreas das ciências e tecnologias. Assim, analisou-se de que forma o espaço não formal de ensino pode ajudar na prática educativa das atividades propostas pelas extensões e de que maneira esses projetos levam o conhecimento de educação em saúde em parasitologia nesses espaços. Além disso, por meio da técnica da Nuvem de Palavras, buscou-se identificar as principais dúvidas sobre os assuntos de parasitologia abordados e também as pré-concepções sobre o tema. Portanto, concluiu-se que o espaço não formal institucionalizado pode ser um grande aliado para o ensino de educação em saúde em parasitologia, pois permite utilizar diferentes metodologias que colaboram para a compreensão da teoria com a prática.
\end{abstract}

Palavras-chave:Saúde. Parasitologia. Educação não formal. Extensão Universitária.

\section{ABSTRACT}

The university extension activities have gained more space for showing up important building instruments of scientific thought, contributing to the incorporation of new knowledge and practices for society and for the extension workers. The non-formal education spaces, in turn, prove to be great ways to make the construction of this knowledge possible. Therefore, through the association of extension activities in nonformal education spaces, it is possible to promote the themes of health education in parasitology, seeking to raise awareness and prevent, in a creative and active way, parasitosis that are still a major public health problem. Thus, this study aimed to report the experience of extension projects of the State University of Rio de Janeiro, LiPar (Liga de Parasitologia) and Educac, the "Week of Girls and Women in Science" event, organized by women from different sciences and technologies. Accordingly,it was analyzed how the nonformal teaching space can help in the educational practice of the activities proposed by the extensions and how these projects take the knowledge of health education in parasitology in these spaces.In addition, through the words of cloud technology, it was sought to identify the main questions about parasitology issues addressed and also the preconceptions on the subject. So, it was concluded that the non-formal institutionalized space can be a great ally for health education teaching in parasitology as it allows you to use different methodologies that contribute to the understanding of theory with practice.

\footnotetext{
${ }^{15}$ Mestre em Microbiologia Médica Humana. UERJ, Rio de Janeiro, RJ, Brasil. E-mail: thainamelo029@gmail.com. Orcid: https://orcid.org/0000-0003-1622-8221

${ }^{16}$ Mestranda em Microbiologia Médica Humana. UERJ, Rio de Janeiro, RJ, Brasil. E-mail: isasilveira6@gmail.com. Orcid: https://orcid.org/0000-0002-7072-3891

${ }^{17}$ Doutoranda em Microbiologia Médica Humana. UERJ, Rio de Janeiro, RJ, Brasil. E-mail: alinearosa.ar@gmail.com. Orcid: https://orcid.org/0000-0002-2505-3710

${ }^{18}$ Graduando em Enfermagem. UERJ, Rio de Janeiro, RJ, Brasil. E-mail: danielbarbosa.jor@gmail.com. Orcid: https://orcid.org/0000-0002-1648-3751

${ }^{19}$ Mestranda em Biologia Humana e Experimental. UERJ, Rio de Janeiro, RJ, Brasil. E-mail: joanabernardo.bio@gmail.com. Orcid: https://orcid.org/0000-0002-4013-6207

${ }^{20}$ Pós-graduação (Doutorado em Ciência e Pós-Doutorado em Helmintologia). Professora Associada da

Universidade do Estado do Rio de Janeiro. UERJ, Rio de Janeiro, RJ, Brasil. E-mail: renataheisler@gmail.com. Orcid: https://orcid.org/0000-0002-5442-0030
} 
Keywords:Health. Parasitology. Non-formal education. University extension.

\section{INTRODUÇÃO}

Os projetos de extensão mostram-se cada vez mais numerosos e relevantes na divulgação dos conhecimentos científicos, uma vez que eles trazem conteúdos complementares ao exigido pela educação formal, aplicando diferentes metodologias e estratégias didático-pedagógicas, de acordo com as necessidades de cada grupo participante, tornando essas atividades extremamente importantes tanto para a sociedade quanto para o aprendizado dos próprios ligantes (FERNANDES et al., 2016). Segundo Scheidemantel, Klein e Teixeira (2004):

A extensão possibilita a formação do profissional cidadão e se credencia, cada vez mais, junto à sociedade como espaço privilegiado de produção do conhecimento significativo para a superação das desigualdades sociais existentes, como prática acadêmica que interliga a Universidade nas suas atividades de ensino e de pesquisa, com as demandas da maioria da população (SCHEIDEMANTEL, KLEIN E TEIXEIRA, 2004, p.1).

Além disso, como apontam Mendonça e Silva (2002), poucas pessoas tem acesso ao conhecimento gerado pelas universidades públicas, e, portanto, a extensão universitária cumpre um papel fundamental para ampliação do acesso a esses conhecimentos, reafirmando a função social da própria universidade.

A Liga de Parasitologia (LiPar) surgiu em 2016, integrado à Faculdade de Ciências Médicas da Universidade do Estado do Rio de Janeiro (FCM) e conta com a participação de 22 discentes. A LIPAR atua em espaços formais, não formais e informais de ensino, promovendo a construção do conhecimento científico entre sociedade e extensionistas, através de práticas de divulgação científica nas temáticas de educação em saúde em parasitologia (NEVES et al., 2019).

O projeto "Educação em Saúde: Prevenção das Doenças Parasitárias (Parasito Educac)”, também da FCM, da Universidade do Estado do Rio de Janeiro (UERJ), conta com 15 graduandos em Enfermagem. O projeto visa levar conhecimentos de Parasitologia para todas as pessoas consideradas "leigas" neste assunto, de forma clara e didática, relacionando a saúde do homem com o meio ambiente, sua comunidade e seus hábitos 
diários que podem influenciar no surgimento de doenças parasitárias e infectocontagiosas (LEAL et al., 2019).

O evento "Semana de Meninas e Mulheres na Ciência" foi fundado pela geóloga Fernanda Campos Furtado, e organizado pelas discentes Gabriela Elias Pereira, Natália Righetto Valente e Rachel Rodrigues Lopes, com o objetivo de estimular meninas em idade escolar a conhecer campos específicos da ciência - que ainda são majoritariamente ocupados por homens - e, com isso, gerar curiosidade que seja capaz de motivá-las a buscar ocupar esses espaços. O evento conta com duas edições já realizadas, ambas nas salas e auditórios dos Institutos de Pesquisa da Geologia, na Universidade do Estado do Rio de Janeiro, com um público médio de 500 pessoas. Na Semana, são oferecidos cursos e palestras de diversas áreas da ciência e tecnologia como Geologia, Física , Biologia, entre outras, proferidos por mulheres, para o público de todos os gêneros e idades.

Buscando atender a proposta do evento, nossos projetos de extensão participaram abordando a temática de educação em saúde na área de parasitologia, utilizando diferentes métodos pedagógicos e buscando ressaltar um pouco do que é o fazer científico. Com isso, o trabalho tem o objetivo de analisar, através do método qualitativo, de que maneira o espaço não formal de ensino colabora com as atividades propostas pelos projetos de extensão, e de que maneira esses projetos levam o conhecimento de educação em saúde em parasitologia nesses espaços. Utilizamos ainda a técnica da Nuvem de Palavras para identificar as principais dúvidas sobre os assuntos de parasitologia abordados no evento e também as pré-concepções sobre a temática.

\section{A EDUCAÇÃO EM SAÚdE E AS PARASITOSES}

Ao longo das décadas, as reflexões e metodologias sobre a educação em saúde foram notavelmente transformadas. Se antes se considerava apenas os quesitos sanitários, com a inserção das questões sociais, passou-se a pensar educação em saúde através de um prisma multifacetado, dando importância também aos fatores das ciências sociais e humanas (GAZZINELLI et al., 2005).

A educação em saúde abarca os conceitos de educação e de saúde (SALCI et al., 2013). Entretanto, apesar de serem diferentes instrumentos de trabalho, eles estão intrinsecamente relacionados quando se pensa no objetivo final desse tipo de educação: 
o primeiro se ocupará de tratar dos métodos pedagógicos, tentando transformar comportamentos, gerar reflexões e crítica, ao passo que o segundo transmitirá conhecimentos científicos para intervir sobre as doenças (FALKENBERG et al., 2014).

O processo educativo é complexo e possui muitas variáveis como a questão cultural, social, psicológica, entre outras, logo, ao pensar em educação em saúde, tem-se que ter em mente que esse processo de compreensão e prática se dará apenas quando os elementos sociais, psicológicos e sanitários puderem estar em consonância com a realidade desses indivíduos. Nesse sentido, a educação em saúde precisa ir além das atividades práticas de transmissão de informações. Uma boa estratégia para desenvolver esse tipo de educação é a utilização do método Círculo de Cultura, proposto pelo educador Paulo Freire, que consiste em uma abordagem horizontal, onde os sujeitos do processo educativo se reúnem para investigar temas próximos de sua realidade e de interesse do próprio grupo, compartilhando experiências em comum, com uma linguagem acessível (SALCI et al., 2013).

A presença do tema saúde nos Temas Contemporâneos Transversais (TCTs) da Base Nacional Comum Curricular (BNCC) exemplifica a mudança das orientações tradicionais acerca do assunto e demonstra a importância de ser trabalhado em todas as etapas de ensino e aprendizagem (SOUZA, GUIMARÃES e AMANTES, 2019), uma vez que tem como objetivos superar concepções fragmentadas de conceitos, tornando-os sistêmicos; problematizar a realidade; promover um processo educativo que seja continuado e comprometido com uma construção de saber coletiva e integrar habilidades para resoluções de problemas (BRASIL, 2019).

No campo da saúde, uma das temáticas relevantes a serem abordadas e que está inserida na BNCC é a parasitologia. As parasitoses são um grupo de doenças que acometem populações que vivem em situação de pobreza ou extrema pobreza, sem saneamento adequado e com contato próximo de agentes infecciosos, gado ou animais domésticos (WHO, 2020). As infecções parasitárias são causadas por helmintos e protozoários, e constituem-se em um importante assunto de saúde pública. Elas apresentam uma vasta distribuição geográfica e podem ocorrer tanto em áreas rurais quanto em áreas urbanas, de acordo com as espécies e ambientes envolvidos (SANTOS, COSTA e CASTRO, 2017). 
Segundo o Ministério da Saúde (2010), as doenças parasitárias são definidas como negligenciadas, pois, embora existam financiamentos para essas pesquisas, há pouca reversão em avanços terapêuticos, e um dos motivos é o desinteresse da indústria farmacêutica nessas temáticas - por não serem lucrativas-, já que atingem majoritariamente as populações mais pobres.

Dentre as parasitoses, podemos destacar as enteroparasitoses, como as mais frequentes em idade escolar (RODRIGUES et al., 2013), sendo responsáveis por altos índices de morbidade. Apesar de grande parte dos casos poderem ser tratados através de medicamentos orais (MELO, FERRAZ e ALEIXO, 2010), alguns dos fatores que colaboram para a alta prevalência dessas doenças, além da falta de saneamento e de condições precárias de vida, são a falta de conhecimento sobre a transmissão e controle das infecções parasitárias e princípios de higiene (RIBEIRO et al., 2013). Dessa maneira, a execução de práticas educativas que visem levar conhecimento à população sobre parasitoses poderá torná-las capazes de atuar na prevenção e redução da carga parasitária (RIBEIRO et al., 2013), além de contribuir para que os indivíduos tenham autonomia e sejam capazes de propor e opinar acerca das decisões de saúde para cuidados individuais e coletivos (FALKENBERG et al., 2014).

\section{AS FORMALIDADES E NÃO FORMALIDADES DA EDUCAÇÃO}

De acordo com Brandão (1985) "ninguém escapa da educação", pois todos nós estamos envolvidos com ela, de múltiplas formas e em diversos espaços de nossas vidas. Neste sentindo, para pensarmos nas modalidades de ensino existentes em nossa sociedade, é necessário compreender que a educação é um conceito amplo, podendo ser analisada a partir de três aspectos: a educação formal, a educação não formal e a educação informal (LIMA et al., 2019).

A educação formal, conforme aponta Brandão (1985), é aquela que se sujeita a uma pedagogia, desenvolve métodos, define critérios e forma executores especializados. Além disso, como acrescentam Cazelli e Coimbra (2013), é promovida pelos sistemas escolares, com regras estabelecidas e focada em conteúdos a serem aprendidos dentro das grades curriculares. 
Em outro sentido, temos a educação não formal e informal. A educação informal é aquela que ocorre de maneira espontânea, na troca com o coletivo, seja através da família, dos amigos, da comunidade, entre outros (VIEIRA, BIANCONES e DIAS, 2005). Já a educação não formal é aquela organizada e sistematizada fora do ambiente formal de ensino, e "ocorre quando existe a intencionalidade de dados sujeitos em criar ou buscar determinados objetivos fora da instituição escolar" (VIEIRA, 2005). De acordo com o Thesaurus Brasileiro da Educação (apud Hartmann, 2012), o alvo da educação não formal está em medir a qualidade da experiência vivenciada - e suas conseqüências -, e não estritamente a aprendizagem dos alunos, atuando de modo complementar à educação formal. Santos e Terán (2013) acrescentam, reforçando que na educação não formal:

Existe a apresentação de um ambiente fora da escola (formal) para um ambiente diferente do conhecido, o que pode produzir 'expectativas para novas experiências'. Procura-se um ambiente onde este conhecimento seja manipulado por profissionais, pesquisadores ou pessoas com experiência nos mesmos para poder compartilhar informações relevantes, ou seja, procura-se "reconhecer novos referenciais de autoridade sobre o objeto de conhecimento no mundo (SANTOS E TERÁN, 2013, p. 5).

Segundo Rocha e Terán (2010), debater sobre os inúmeros avanços proporcionados à sociedade pelas ciências é cada vez mais necessário para a alfabetização científica da população. Ambientes reconhecidos de divulgação científica e cultural, institucionalizados ou não, sem a obrigação de um programa de estudos fechado e normatizado, promovem ganhos para além da aprendizagem de conceitos (SANTOS e TERÁN, 2013). Neste sentido, Hartmamm (2012) diz que a educação científica não formal é responsabilidade de diversas instituições que têm por principal objetivo "divulgar a ciência e a tecnologia para um público amplo" (HARTMANN, 2012; CATARINO et al., 2017). Neste sentido, os espaços e casas de ciências, museus, institutos e universidades permitem explorar e promover a reflexão, as curiosidades e a aquisição de competências por parte de estudantes.

Os espaços de ensino podem ser divididos em espaços formais, não formais e informais (VIEIRA, BIANCONE e DIAS, 2005; JACOBUCCI, 2008). O espaço formal abrange a escola garantida por leis, com todas suas dependências (JACOBUCCI, 2008), formada por currículos, divididas pela faixa etária e nível de conhecimento (CASCAIS e 
TERÁN, 2014; CATARINO et al., 2017), onde se espera, ao final do aprendizado, obter titulação (GOHN, 2006).

A definição de espaço não formal proposta por Jacobucci (2008) é a de que se trata de qualquer espaço diferente da escola onde podem ocorrer ações educativas. Esses espaços podem ser definidos em: 1) Institucionalizado, cujos espaços são regulamentados e contam com equipe para auxiliar nas atividades executadas, tendo os museus, institutos de pesquisas, centros de ciência, zoológicos, entre outros, e; 2) Não-Institucionalizado, que são os que não dispõem de organização institucional, como parques, praia, teatro, rua, praças e outros.

Segundo Gohn (2006), existem outras maneiras de delimitar as diferenças existentes entre o espaço formal e não formal de ensino, para além da definição, que é pensar quem são os educadores de cada campo. No primeiro, sabemos que são os professores, já no segundo, os agentes do desenvolvimento da educação não formal são pessoas como pesquisadores, extensionistas, discentes, entre outros. A autora também nos diz que nos espaços não formais existe uma intencionalidade educativa que muitas vezes se articula com temáticas da educação formal, pois a educação nesses espaços precisa ter sempre alguma proposta pedagógica.

Considerando que a escola é um espaço de gênese da construção do conhecimento, e não só de transmissão, é preciso que se respeite o tempo e as necessidades dos estudantes. Logo, é inviável que a escola seja responsável por todo processo educativo. Ademais, deve-se levar em consideração que ainda existem muitas pessoas que passam pouco tempo frequentando as escolas e também por esse motivo é necessário que haja possibilidade dessas pessoas continuarem a aprender depois de saírem das instituições (ROCHA e FACHÍN-TERÁN, 2010).

Muitos são os espaços que contribuem para divulgação e construção de conhecimentos para a população, de modo a colaborar para o desenvolvimento pessoal e social, como os espaços não formais e informais de ensino. É neste sentido que, apesar da universidade parecer, a priori, apenas um local formal de ensino, ela possui em seu interior uma hibridização de espaços, a depender do público alvo e do que se propõem as atividades. Portanto, a universidade conta com: a) espaços formais de ensino, que, segundo Jacobucci (2008), são aqueles onde a educação realizada é formalizada, garantida por Lei e organizada a partir de uma padronização nacional; b) não formais, que 
pode ser qualquer espaço da universidade destinado a receber visitação de estudantes externos, internos e da comunidade na busca e inovação para os processos de ensino e aprendizagem (COELHO, BREDA e BROTO, 2015) que não tenham relação com o ensino formal e; c) espaços informais, onde ocorrem trocas espontâneas de conhecimento, como praças, clubes de leituras, bosque e outros.

Os espaços não formais, por serem externos aos espaços escolares, permitem uma maior flexibilização de metodologias que vão surgindo a partir de percepções da vida cotidiana como as culturais, de classe, entre outras, e faz com que as práticas sejam colocadas em ação de acordo com as necessidades mostradas pelos grupos, conseguindo, dessa maneira, adentrar o campo simbólico e afetivo desses indivíduos (GOHN, 2006), podendo tornar o conhecimento mais significativo.

\section{METODOLOGIA}

As atividades extensionistas da LiPar e Educac, no evento "Semana de Meninas e Mulheres na ciência”, tiveram duração de cinco dias e ocorreram em salas dos Institutos de Pesquisa da Geologia, no quarto andar da Universidade do Estado do Rio de Janeiro, tendo como público alvo estudantes do ensino fundamental e médio. Ao longo do evento, participaram das ações 22 extensionistas, sendo 13 biólogas(os) e 9 discentes em enfermagem. Ao final dos cinco dias da Semana, passaram pelas atividades em torno de 60 meninas de diferentes faixas etárias e instituições escolares. Com isso, as estratégias metodológicas foram adaptadas às necessidades de cada grupo etário.

De acordo com a resolução n ${ }^{\circ} 466 / 2012$ do Conselho Nacional de Saúde, todos os seres humanos engajados ativamente em pesquisas e trabalhos científicos, devem ser tratados com dignidade, respeito, ética e moral. Desta maneira, durante as ações com crianças e adolescentes houve compromisso, confidencialidade e sigilo. O projeto faz apenas exposição de materiais de apoio e educativos, como modelos em biscuit, para que os alunos se aproximem dos conceitos da Parasitologia e em todas as ações do projeto nós fornecemos o Termo de Consentimento Livre e Esclarecido (TCLE).

Os materiais utilizados nessas ações foram modelos didáticos, construídos em biscuit, de parasitos helmintos como Ascaris lumbricoides, Trichuris trichiura, Enterobius vermicularis (Figura 1A e 1B1 e 1B2), Schistosoma mansoni, proglote 
madura de Taenia sp., e os protozoários Leishmania sp. e Trypanosoma cruzi. Além dos modelos em pelúcia do protozoário Giardia lamblia, dos helmintos Taenia saginata (Figura 1C2 e 1C3), Ancylostomaduodenale, T. trichiura e do ectoparasito Pediculus humanus (Figura 1C1). Também foram utilizados espécimes reais de helmintos conservados em formol, A. lumbricoides, Taenia sp. (Figura 2), S. mansoni e T. trichiura.

Figura 1 - Modelos didáticos, em biscuit, dos parasitos A) Ascaris lumbricoides, B1) Enterobius vermicularis, B2) Trichuris trichiura e os modelos, em pelúcia, do ectoparasito C1) Pediculus humanus e dos parasitos C2) Giardia lamblia e C3) Taenia saginata.

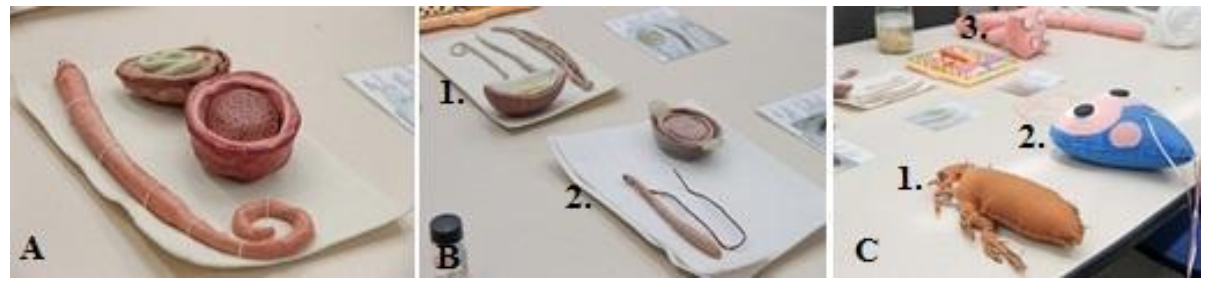

Fonte: Fotos oficiais do evento Semana de Meninas e Mulheres na ciência (2019).

Figura 2 - Vidros contendo A) Ascaris lumbricóides, em um pedaço de intestino e B) Taenia $s p$. conservados em formol.

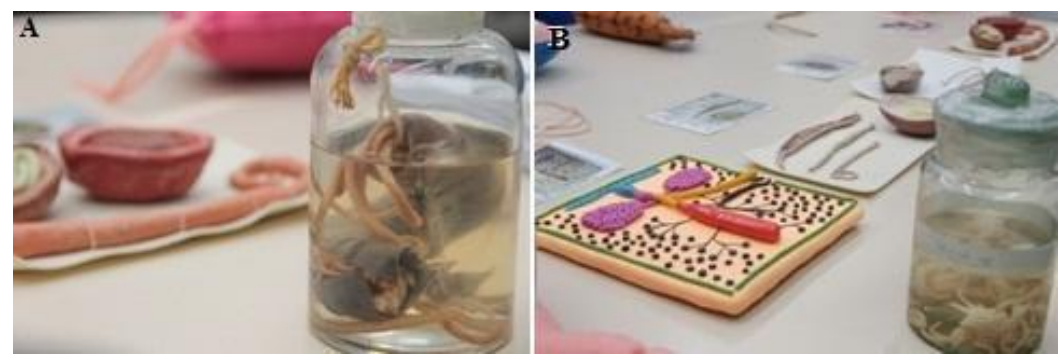

Fonte: Fotos oficiais do evento Semana de Meninas e Mulheres na ciência (2019).

O uso de diferentes modelos de parasitos ajuda a mostrar, de maneira didática e divertida, a estrutura e as características dos parasitos, e também despertam maior interesse do público alvo, posto que são palpáveis e coloridos. Eles eram mostrados a cada explicação dialógica, de acordo com a temática abordada, e deixados para visualização e contato a qualquer momento. Ademais, utilizaram-se banners que discorriam sobre tricomoníase, pediculose e enteroparasitoses (Figura 3) para explicar dialogicamente sobre as doenças e suas profilaxias.

Figura 3 - Banners sobre A) tricomoníase, B) pediculose e C) enteroparasitoses. 


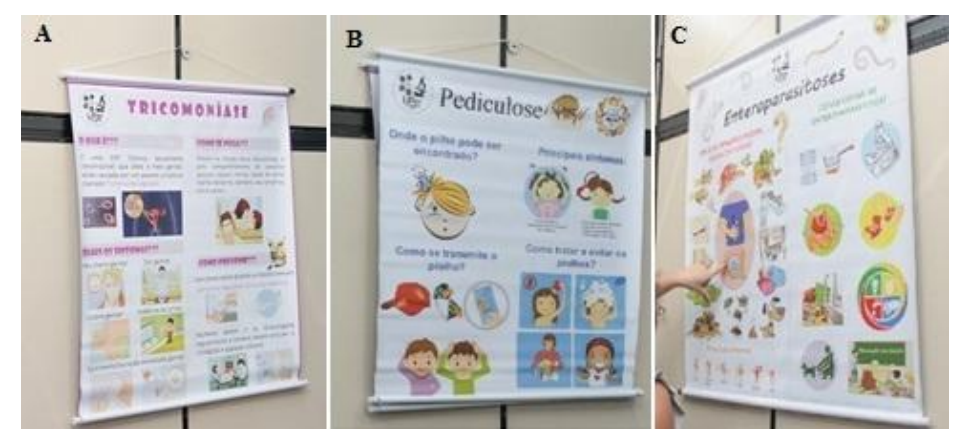

Fonte: Fotos oficiais do evento Semana de Meninas e Mulheres na ciência (2019).

Entretanto, devido à presença de grupos etários diferenciados, as conversas sobre tricomoníase, que é uma IST's (infecção sexualmente transmissível), foram abordadas apenas com as meninas do ensino médio. Ao final, para esse grupo, eram distribuídos folders explicativos sobre o assunto e preservativos. As pediculoses, por sua vez, foram abordadas apenas para as meninas do ensino fundamental, uma vez que é nessa faixa etária que mais surgem os problemas de piolho. Em todas as faixas etárias discorreu-se sobre as enteroparasitoses e, ao final de cada diálogo, foi realizado o ensino da lavagem de mãos. Após essas atividades, todas as meninas eram divididas em filas para poderem ver lâminas de parasitos no microscópio óptico e o ectoparasito $P$. humanus na lupa, em uma tentativa de aproximar a parte pedagógica da prática científica. Todos os materiais utilizados nessas ações pertencem ao acervo da Disciplina de Parasitologia da UERJ e foram elaborados por extensionistas dos cursos de biologia e enfermagem.

Os extensionistas tiveram como proposta pedagógica o método da investigação dialógica (SOFISTE, 2007). Primeiramente, buscou-se relacionar a temática com o cotidiano do público alvo e, a partir disso, dialogar sobre o conhecimento prévio que esses possuíam sobre os assuntos abordados e, somente após isso, através das colocações do público, construir o conhecimento acerca dos temas. Dessa forma, pretendeu-se tornar o público alvo protagonista na construção de sentido das propostas, fazendo com que esses não sejam meros ouvintes.

Para a análise deste trabalho, optou-se pela investigação qualitativa de Bogdan e Biklen (1994), que possui como uma de suas características o recolhimento de dados a partir de observações e imagens. Para realizar as observações, foi utilizado o método da “observação participante” proposta de Kluckhohn (2018), que a define da seguinte maneira: 


\begin{abstract}
A "observação participante" é a co-participação consciente e sistemática, tanto quanto as circunstâncias permitirem, nas atividades comuns de um grupo de pessoas e, se necessário, nos seus interesses, sentimentos e emoções. O propósito deste método é obter dados sobre o comportamento através de contactos diretos, em situações específicas, nas quais a distorção resultante do fato de ser o investigador agente estranho é reduzida ao mínimo (KLUCKHOHN, 2018, p. 29).
\end{abstract}

Além disso, utilizamos também a técnica da Nuvem de Palavras, como recurso complementar para apresentação de resultados da investigação qualitativa. De acordo com Vilela, Ribeiro e Batista (2020), esta técnica consiste em uma representação gráficovisual que dá maior destaque às palavras que aparecem mais frequentemente em textos, questionários entre outros escritos. Desta forma, quanto mais uma palavra for citada, mais destacada será sua representação no gráfico, com tamanhos e cores diferentes para cada palavra, de acordo com sua freqüência, enfatizando sua relevância.

A fim de criar a Nuvem de Palavras selecionamos, dentre as anotações feitas durante o evento, as perguntas realizadas pelo público, de modo a identificar quais são as principais dúvidas existentes sobre os assuntos de parasitologia abordados e também as pré-concepções sobre o tema. Para gerar a Nuvem de Palavras utilizamos o website gratuito Wordart.com, que permite utilizar frases e expressões, e não apenas palavras individuais.

\title{
RESULTADOS E DISCUSSÃO
}

Ao longo da experiência dos projetos de extensão LiPar e Educac, no evento em questão, percebeu-se que os espaços não formais de ensino contribuem significativamente para o processo de ensino-aprendizagem por múltiplos fatores, sendo um deles o espaço físico. Nem sempre existem laboratórios nas escolas que possam ser utilizados como recurso de aproximação entre o ensino e a prática científica, acarretando em prejuízo no desenvolvimento dos conteúdos obrigatórios de ciências.

Portanto, ao possibilitar que o público entrasse em contato com objetos como o microscópio óptico e a lupa, buscou-se aproximá-los da prática científica, identificando os parasitos a partir de suas características e morfologias, e explicando de que maneira as lâminas são preparadas. Foi perceptível o interesse do público de todas as faixas etárias 
na hora de manusear o microscópio, sendo a atividade mais atrativa, o que corrobora o quanto esses objetos são incomuns na realidade desses indivíduos.

Outro fator está associado às questões emocionais. De acordo com Gohn (2006), a educação não formal deve ser praticada por meio de métodos interativos, buscando atuar no campo das emoções. Neste sentido, foi observado que nos espaços não formais de ensino, pelos agentes da ação não serem professores e por não serem atividades passíveis de avaliação com nota, percebeu-se que os indivíduos sentem-se mais livres para perguntar, refletir e demonstrar o que sabem, diminuindo a preocupação com supostos erros e, tornando as ações muito mais enriquecedoras e cheias de propósito.

Durante as atividades expositivas sobre as enteroparasitoses, a tricomoníase e a pediculose, recorreu-se novamente ao método da investigação dialógica, tentando sempre empregar uma linguagem didática e dinâmica, a fim de facilitar o aprendizado e de instigar o público a participar da ação. Através dessa troca, foi observado que muitas meninas não conheciam o que era tricomoníase e desconheciam que esta é um IST (Infecção Sexualmente Transmissível), afirmando que emprestavam objetos pessoais -, que podem servir como veículos de transmissão do parasito - como toalhas e biquínis, para amigas e/ou parentes íntimas. Além disso, também foi observado que algumas delas tiveram dificuldade de fazer correlação entre a prevalência de parasitoses intestinais em áreas pobres e ausência de políticas públicas sanitárias.

Outra questão a ser destacada é o fato de que a maior parte das meninas, ao serem indagadas sobre quais os parasitos conheciam, de forma unânime, responderam "vermes", seguidos de conceitos pessoais acerca deste, como "nojento" e outros adjetivos que indicavam repulsa. Também eram poucas as que se lembravam de outros tipos de parasitos, como os protozoários, por exemplo. Apesar disso, grande parte do público detinha conhecimentos corretos acerca dos helmintos, ainda que não soubessem o nome das doenças causadas por esses, pois sabiam que parasitos como o verme, ao infectarem uma pessoa, poderiam levá-la a um possível quadro de diarreia, vômito e perda de peso, por se estabelecerem nos intestinos, além de reconhecer que as profilaxias para esse tipo de doença se dão através de hábitos de higiene, como lavar bem os alimentos e as mãos.

Através dessas observações pode-se perceber o quão importante é divulgar a temática de educação em saúde, pois, segundo Ribeiro et. al (2013), a implementação de práticas educativas nessa área possibilita que as pessoas adquiram conhecimentos sobre 
as parasitoses, fazendo com que elas sejam capazes de atuar na prevenção e redução da carga parasitária. Ademais, essas práticas pedagógicas, além de colaborarem na emancipação do indivíduo, têm o potencial de conscientizá-los e mobilizá-los para que sejam capazes de intervir de forma individual ou coletiva nas decisões que podem interferir diretamente na qualidade de vida (SACI et al., 2013).

A utilização dos modelos didáticos de parasitos pelas ligas visa apresentar ao público, de forma lúdica, as diferentes características e morfologias dos parasitos. Segundo Fernandes et al. (2016), as atividades de educação em saúde para jovens e crianças só despertam interesse caso as metodologias sejam adequadas para cada faixa etária. Logo, os modelos didáticos utilizados, feitos em biscuit, pelúcia e até mesmo os espécimes reais, contribuíram para que a disponibilidade de diferentes modelos táteis e visuais de observação dos parasitos garantisse que todas as faixas etárias pudessem ser contempladas.

Os modelos em biscuit possibilitam que as características e as morfologias sejam mais fidedignas possíveis com as encontradas nos parasitos, uma vez que o material é mais maleável, permitindo assim uma maior precisão. Como o ensino de parasitologia compreende ciclos de vida complexos e com parasitos em diferentes morfologias, pode ser dificultoso para os alunos criarem uma imagem mental e assimilar os conceitos. Sendo assim, a utilização de modelos didáticos como ferramenta auxiliar no processo de ensinoaprendizagem com jovens é extremamente benéfica, pois facilita o aprendizado e a representação de conceitos (ZIERER, 2017). Com isso, foram utilizados esses modelos para falar sobre as doenças parasitárias, seus agentes etiológicos, os modos de transmissão e também as profilaxias. A partir da visualização dos modelos, questionamentos referentes às estruturas foram criados, como, por exemplo, o porquê de um parasito ser maior que o outro e possuir curva em uma ponta e o outro não (Figura 4). A partir dessa observação, ficou constatada a importância dos modelos didáticos e conseguiu-se construir um caminho para a questão teórica sobre o fato de que fêmeas do parasito em questão, o E. vermicularis, são maiores e possuem uma extremidade mais larga e outra mais afilada, enquanto o macho, por sua vez, é menor e possui a extremidade curvada.

Figura 4 - Modelo didático de um parasito fêmea (A), macho (B) e um ovo (C) de Enterobius vermiculares. 


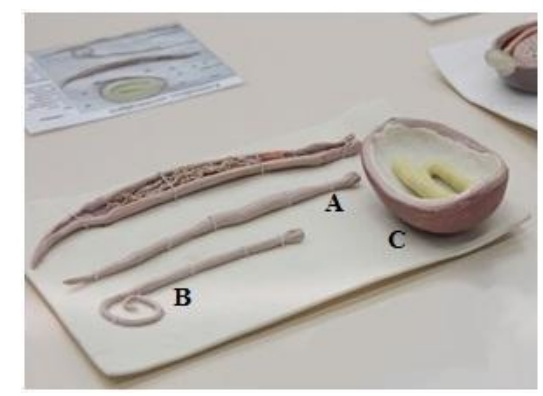

Fonte: Fotos oficiais do evento Semana de Meninas e Mulheres na ciência (2019).

A utilização dos modelos em pelúcia, por sua vez, é ótima para o uso com crianças pequenas, pois elas entendem aquele objeto como um brinquedo. Segundo Carvalho (2016):

O brinquedo coloca a criança na presença de reproduções: tudo o que existe no cotidiano, a natureza e as construções humanas. Pode-se dizer que um dos objetivos do brinquedo é dar à criança um substituto dos objetos reais, para que possa manipulá-los. Enquanto objeto, é sempre suporte da brincadeira (CARVALHO, 2016, p.26).

Logo, nos ajuda a mergulhar no mundo lúdico da criança, tornando possível a conexão com ela. Dessa forma, foi possível ensinar a importância dos cuidados básicos de higiene, como ensinar a importância de lavar as mãos e de não as levar à boca, fazendoas compreender que, sem essas práticas, elas poderiam adquirir esses indesejáveis parasitos.

A utilização de espécimes reais de parasito tem o intuito de aproximar o ensinoaprendizagem da prática científica, uma vez que leva os objetos de estudo de laboratórios para as ações feitas pelos extensionistas permitindo a compreensão de que temas do currículo formal podem ser científicos e ter um conteúdo para além do que é usualmente ensinado.

Ao final das ações, foi questionado às meninas se elas sabiam lavar as mãos. Essa pergunta sempre trazia bastante surpresa, porque, afinal, sugere um ato simples que pode ser feito de qualquer maneira. Entretanto, foi explicado que a higienização das mãos tem um método correto que precisa ser seguido, caso o objetivo seja ter as mãos devidamente higienizadas, e que esse método é utilizado por médicos (as) e enfermeiros (as) para evitar 
disseminação de micro-organismos patogênicos aos pacientes e aos próprios profissionais. Além disso, informou-se que o sabão precisa ficar em contato com a pele das mãos por ao menos 30 segundos, para produzir eficácia. Essas informações causaram espanto e questionamentos sobre sua utilização. Entretanto, todas elas se mostraram bastantes curiosas para saber o método correto de lavagem das mãos e, logo após a demonstração das extensionistas, elas mesmas continuaram a repetir o ato até a fixação das etapas. A partir dessa percepção, o uso da prática de ensino de lavagem das mãos se mostra bastante interessante no que diz respeito à aceitação do público, e, em tempos de pandemia, se torna essencial para evitar a disseminação e infecção por viroses e outros micro-organismos patogênicos.

Com o intuito de constatar as principais indagações que ocorreram durante as diferentes atividades feitas pelos extensionistas, foi elaborada a nuvem de palavras abaixo (Figura 5).

Figura 5 - Nuvem de Palavras formadas por questionamentos feitos pelo público alvo, elaborada através do website wordart.com.

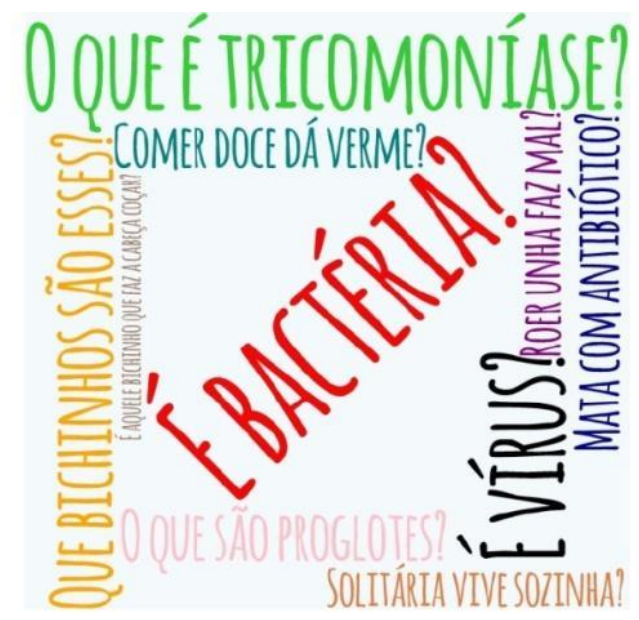

Fonte: Autoria própria(2020).

Conforme já mencionado, percebemos que muitas meninas tinham dúvidas sobre o que é tricomoníase. Além disso, grande parte do público adolescente questionava se os modelos didáticos apresentados nas atividades eram bactérias ou vírus, demonstrando que esses micro-organismos são mais conhecidos popularmente que os parasitos. Enquanto que para as crianças a pergunta mais comum era "Que bichinhos são esses?", reconhecendo que se trata de seres vivos. Também foi verificada a existência, por parte de algumas participantes, de uma noção sobre o uso de antibióticos como meio de 
combater doenças causadas por micro-organismos, sem identificar, porém, que por se tratarem de parasitos, este método não tem eficácia.

Ademais, foi possível verificar que uma pequena parte do público apresentou a ideia de que a ingestão de doces seria a causadora de "vermes", reafirmando que algumas informações acerca do tema são preconcebidas, muitas vezes adquiridas através da família e do senso comum, além da generalização dos parasitos por meio do termo "verme".

Segundo Gohn (2006), na educação não formal, os resultados esperados muitas vezes podem não ser visualizados instantaneamente pelos agentes da ação. Porém, isso não significa que não houve aprendizagem, pois essa pode se estabelecer de outras formas, como, por exemplo, ao ser externalizada para o cotidiano, no encontro com amigos, parentes, e até mesmo na educação no âmbito formal. Por fim, espera-se que essas ações contribuam para que o indivíduo se sinta parte da comunidade, podendo participar de forma ativa, criativa e crítica na sociedade, fortalecendo o exercício da cidadania (CAZELLI, 2005).

\section{CONSIDERAÇÕES FINAIS}

Os projetos de extensão têm se mostrado um espaço importante para a divulgação do conhecimento científico em educação em saúde na área de parasitologia e para a produção de pesquisa. As potencialidades educacionais propostas pelas práticas das ligas vão além do que é feito nas ações, tanto para o público alvo, que pode levar o conhecimento adquirido para o seu dia a dia, podendo modificar as próprias práticas de saúde, quanto para os extensionistas, que adquirem, através dessas ações, experiências e reflexões que contribuem para a formação profissional dos mesmos.

Os espaços não formais de ensino apresentam-se como terrenos férteis para trabalhar as possibilidades que os espaços formais podem não oferecer, como, por exemplo, a utilização de diferentes materiais pedagógicos que propiciam uma relação entre a teoria e a prática, possibilitando um aprendizado mais participativo e reflexivo. Dessa maneira, fazendo planejamentos estratégicos acerca do espaço, das metodologias e do público alvo, é possível explorar os espaços não formais de maneira bastante didática 
e dialógica, criando ações pedagógicas de ensino-aprendizagem que sejam relevantes para os indivíduos e para a sociedade.

\section{AGRADECIMENTOS}

Gostaríamos de agradecer à organização da Semana de Meninas e Mulheres na Ciência pela oportunidade de participar do evento, em especial às geólogas Camila Nogueira, Fernanda Campos Furtado e Rachel Rodrigues Lopes. Também agradecemos à fotógrafa, Suelen Gouvêa, por nos ceder as fotografias do evento, que foram de extrema importância para a confecção deste trabalho.

\section{REFERÊNCIAS}

BOGDAN, R.; BIKLEN, S. Investigação qualitativa em educação: uma introdução à teoria e aos métodos. Porto: Porto Editora, 1994.

BRANDÃO, Carlos Rodrigues. O que é educação. 19. ed. São Paulo: Brasiliense, 1985 .

BRASIL. Ministério da Educação. Temas Contemporâneos Transversais na BNCC. Propostas de Práticas de Implementação. MEC, Brasília, DF, 2019. Disponível emhttp://basenacionalcomum.mec.gov.br/images/implementacao/guia_pratico_temas_c ontemporaneos.pdf . Acessado em 20 de Agosto de 2020.

CARVALHO, M. da C. A importância do brincar na construção de conhecimentos de crianças na pré-escola. 2016. Dissertação (Mestrado em Administração Escolar e Administração Educacional) - Universidade Fernando Pessoa, Porto, 2016.

CASCAIS, M. das G. A.; TERÁN, A. F. Educação formal, informal e não formal na educação em ciências. Ciência em Tela, v. 7, n. 2, p. 1-10, 2014.

CATARINO, G. F. C.; QUEIROZ, G. R. P. C.; BARBOSA-LIMA, M. C. A. O formal, o não formal e as outras formas: a aula de física como gênero discursivo. Rev. Bras. Educ., Rio de Janeiro, v. 22, n. 69, p. 499-517, Junho, 2017.

CAZELLI, S. Ciência, Cultura, Museus, Jovens E Escolas: Quais As Relações?, 2005. Tese (Doutorado em Educação) - Pontifícia Universidade Católica, Rio de Janeiro, 2005 .

CAZELli, S.; COIMBRA, C. A. Q. Proposta para a avaliação da prática pedagógica de professores. Ensino em Re-Vista, Uberlândia: UFU, v. 20, n. 1, p. 133$148,2013$. 
COElho, G. R.; BREDA, V. de C.; BROtTo, T. R. de A. Atividades em um centro de um centro de ciências: motivos estabelecidos por educadores, suas concepções e articulações com a escola. Educ. Pesqui., São Paulo, v. 42, n.1, p. 525538, abr./jun, 2016.

FALKENBERG, M. B. et al. Educação em saúde e educação na saúde: Conceitos e implicações para a saúde coletiva.Ciencia e Saude Coletiva, v. 19, n. 3, p. 847-852, 2014.

FERNANDES, K. J. S. de S. et al. Relato de experiência: vivências de extensão na comunidade. Revista Ciência em Extensão, v. 12, n. 1, p. 97-104, 2016.

GOHN, G. M. Da sociedade civil e estruturas colegiadas nas escolas. Anais do Primeiro Congresso Internacional de Pedagogia social, v. 1, p. 27-38, 2006.

GAZZINELLI, M. F. et al. Educação em saúde: conhecimentos, representações sociais e experiências da doença. Cad. Saúde Pública, Rio de Janeiro, v. 21, n. 1, p. 200-206, 2005 .

HARTMAnN, A. M. O Pavilhão da Ciência: a participação de escolas como expositoras na Semana Nacional de Ciência e Tecnologia. 2012. Tese (Doutorado em Educação em Ciências e Matemática) - Faculdade de Educação, Universidade de Brasília, 2012.

JACOBUCCI, D. F. C. Contribuições dos espaços não-formais de educação para a formação da cultura científica. Em Extensão, v. 7, p. 55-66, 2008.

KLUCKHOHN, F. R. O Método de Observação Participante no Estudo de Pequenas Comunidades. Sociabilidades Urbanas - Revista de Antropologia e Sociologia, v. 2, n. 5, p.29-38, 2018.

LEAL, C. M. C. et al. Vivenciando a Extensão Universitária na formação dos discentes de enfermagem através de ações de Educação em Saúde em Parasitologia: associação entre teoria e prática. Ciências da Saúde: Campo Promissor em Pesquisa 3. 1ed.: Atena Editora, p. 261-273, 2020.

LIMA, E. I et al. O papel da educação formal, não formal e informal na formação política de mulheres educadoras. Revista Pegada - v. 20, n. 1, p.270-286, 2019.

MELO, E. M.; FERRAZ, F. N., ALEIXO, D. L. Importância do estudo da prevalência deparasitos intestinais de crianças em idade escolar.SaBiosRevSaudeBiol 2010; 5:43-47, 2010.

MENDONÇA, S. G. L.; SILVA, P.S. Extensão Universitária: Uma nova relação com a administração pública. Extensão Universitária: ação comunitária em universidades brasileiras. São Paulo, v. 3, p. 29-44, 2002. 
MINISTÉRIO DA SAÚDE. Departamento de Ciência e Tecnologia. Secretaria de Ciência, Tecnologia e Insumos Estratégicos. Doenças negligenciadas: estratégias do Ministério da Saúde. Revista de Saúde Pública, São Paulo, v. 44, n. 1, p. 200-202, 2010.

NEVES, R. H. et al. Contribuição social e acadêmica da Liga de Parasitologia da Universidade do Estado do Rio de Janeiro.In: Nayara Araújo Cardoso; Renan Rhonalty Rocha; Maria Vitória Laurindo. (Org.). As Ciências Biológicas e da Saúde na Contemporaneidade 4. 1ed.: Atena Editora, p. 113-123, 2019.

RIBEIRO, D. F. et al. Educação Em Saúde: Uma Ferramenta Para a Prevenção E Controle De Parasitoses. Revista da Universidade Vale do Rio Verde, v. 11, n. 2, p. 300-310, 2013.

ROCHA, S. C. B. DA; FACHÍN-TERÁN, A. O uso de espaços não-formais como estratégia para o Ensino de Ciências. Manaus: UEA Edições, 2010.

RODRIGUES, R. M et al. Parasitoses intestinais: intervenção educativa em escolares. In: VI Encontro Regional Sul de Ensino de Biologia (EREBIO-SUL), 2013.

SALCI, M. A. et al . Educação em saúde e suas perspectivas teóricas: algumas reflexões. Texto contexto - enferm., Florianópolis, v. 22, n. 1, p. 224-230, 2013.

SANTOS, D. N.; COSTA, P. R. R. S.; CASTRO, N. J. C. Saberes sobre parasitoses em uma comunidade ribeirinha. Revista Interdisciplinar de Estudos em Saúde, v. 6, n. 2, p. 44-56, 2017.

SCHEIDEMANTEL, S. E. ; KLEIN, R.; TEIXEIRA, L. I. A Importância da Extensão Universitária: O Projeto Construir. In: $2^{\circ}$ Congresso Brasileiro de Extensão Universitária 2004, Belo Horizonte. Terceiro Encontro Nacional de Avaliação Institucional de Extensão Universitária, 2004.

SEIFFERT-SANTOS, S. C.; FACHÍN-TERÁN, A. Uma proposta de compreensão e metodologia para o uso dos Espaços Não Formais no ensino de Biologia. In: FACHÍN-TERÁN, A. \& SEIFFERT-SANTOS, S. C. (Orgs.). Novas perspectivas de ensino de ciências em Espaços Não Formais amazônicos. Manaus: UEA Edições, 2013.

SOUSA, M. C.; GuimarÃeS, A. P. M.; AMANTES, A. A Saúde nos Documentos Curriculares Oficiais para o Ensino de Ciências: da Lei de Diretrizes e Bases da Educação à Base Nacional Comum Curricular. Revista Brasileira de Pesquisa em Educação em Ciências, v. 19, p. 129-153, 2019.

SOFISTE, J. G.. Sócrates e o Ensino da Filosofia: Investigação Dialógica - Uma pedagogia para a docência de filosofia. Petrópolis: Editora Vozes, 2007.

VIEIRA, V. da S. Análise de espaços não-formais e sua contribuição para o ensino de Ciências. 2005. 205 f. Tese (Doutorado) - Instituto de Bioquímica Médica, Universidade Federal do Rio de Janeiro, Rio de Janeiro, 2005. 
VIEIRA, V.; BIANCONI, M. L.; DIAS, M. Espaços não-formais de ensino e o currículo de ciências. Ciência e Cultura, v. 57, n. 4, p. 21-23, 2005.

VILELA, R. B., RIBEIRO, A., BATISTA, N. A. Nuvem de palavras como ferramenta de análise de conteúdo: Uma aplicação aos desafios do mestrado profissional em ensino na saúde. Millenium, 2(11), 29-36, 2020.

WORLD HEALTH ORGANIZATION. Neglected tropical diseases. Disponível em https://www.who.int/neglected_diseases/diseases/en/ Acesso em 20 de Agosto de 2020.

ZIERER, M. D. S. A construção e a aplicação de modelos didáticos no ensino de Bioquímica. Revista de Ensino de Bioquímica, v. 15, p. 202, 2017.

Recebido em: 29 de outubro de 2020.

Aceito em: 21 de janeiro de 2021. 